\title{
Dementia in the National Cause of Death Registry in Norway 1969-2010
}

\author{
Vidar Hjellvik ${ }^{1}$, Knut Engedal ${ }^{2}$, Marte Handal $^{1}$, Trond Peder Flaten ${ }^{3}$, Ellen Melbye Langballe ${ }^{1}$, \\ Randi Selmer ${ }^{1}$ and Bjørn Heine Strand ${ }^{1}$ \\ 1) Norwegian Institute of Public Health, P.O. Box 4404 Nydalen, NO-0403 Oslo, Norway \\ 2) Norwegian Centre for Ageing and Health, Oslo University Hospital HF, Ullevål, Building 37, NO-0407 Oslo, Norway \\ 3) Department of Chemistry, Norwegian University of Science and Technology, NO-7491 Trondheim, Norway \\ Correspondence: Vidar HjellvikＥ-mail: vidar.hjellvik@fhi.noＴelephone: +47 21078266
}

\begin{abstract}
Background: The prevalence of dementia is expected to increase markedly during the coming decades. Epidemiological studies involving the National Cause of Death Registry (NCDR) may be useful for exploring the aetiology of dementia. We therefore wanted to study developments in the reporting of dementia in the NCDR over the last four decades.

Methods: We calculated the age- and gender specific proportion of deaths with dementia reported in the NCDR (dementia deaths) in the period 1969-2010, and the proportion of vascular dementia and Alzheimer's disease deaths in 1986-2010. Separate analyses were done for deaths occurring in nursing homes in 1996-2010. The proportion of dementia deaths where dementia was coded as underlying cause of death was also calculated.

Results: The proportion of dementia deaths increased more than threefold in the period 1969-2010 among women (from $4 \%$ to $15 \%$ ), and more than doubled among men (from 3\% to 7\%). In nursing homes the proportion increased from $17 \%$ to $26 \%$ for women and from $13 \%$ to $18 \%$ for men. The proportion of dementia deaths with Alzheimer's disease reported in the NCDR increased from practically zero in 1986 to a maximum of $28 \%$ in 2005 . The proportion of dementia deaths with dementia as underlying cause of death increased from a minimum of $6 \%$ in 1972 to a maximum of $51 \%$ in 2009 .

Conclusion: Although the reporting of dementia in the NCDR increased markedly from 1969 to 2010 , dementia is still under-reported for old people and for deaths occurring in nursing homes when compared to prevalence estimates.
\end{abstract}

\section{INTRODUCTION}

The prevalence of dementia is difficult to estimate (1), but in 2010 there were probably about 70,000 persons with dementia in Norway (2). About $50-70 \%$ of all dementia cases are generally assumed to be Alzheimer's disease (AD) (3). Dementia is strongly related to age, with the prevalence in western Europe varying from about $1-2 \%$ in the age group 65-69 years to about $25 \%$ (4) or $35 \%$ (2) in the age group $85+$. Some studies indicate that the prevalence of AD is higher in women than in men, whereas vascular dementia is more equally distributed between the genders $(5,6)$.

Tomorrow's elderly may have lived healthier lives than yesterday's elderly, which may make them less susceptible to dementia, in particular to vascular dementia. In a Swedish study, the prevalence in the age group 85+ increased in the period 2000/2002 to 2005/ 2007 (7), whereas a Dutch study suggested a decrease in prevalence in all age segments from 1990 to 2000 (8). But as the number of old people is expected to increase drastically during the coming decades - Statistics Norway expects the number of people aged 67 years and older to double over the next $40-50$ years in Norway (9) - a marked increase in the prevalence of dementia can be expected. There is therefore an urgent need to find new clues to the aetiology of dementia, and epidemiological studies involving central health registries like the National Cause of Death Registry (NCDR) may be useful for this purpose (10). Knowledge of the developments in the reporting of dementia diagnoses in the NCDR is therefore important.

Most demented people in Norway end their lives in nursing homes, and most people in Norwegian nursing homes have dementia (11). Still, many of them do not have a dementia diagnosis. In a study from $2007,81 \%$ of 1163 patients in 26 Norwegian nursing homes had dementia according to the Clinical Dementia Rating (CDR) Scale, but only $55 \%$ of those with dementia according to CDR had a dementia diagnosis in their records (11). An even lower percentage could be expected to have dementia reported on the death certificate (12).

The aim of the present work was to study how the coding of dementia in general - and AD and vascular dementia in particular - in the NCDR developed in the period from 1969 to 2010 . We also studied trends in the coding of the diagnosis of dementia as underlying cause of death over the period. Finally, we wanted to study to which degree the higher prevalence of dementia in nursing homes than in the general population was reflected in the NCDR. 
Table 1. Number of deaths in the NCDR in 1969-2010 with dementia diagnoses coded according to International Classification of Diseases (ICD), Revisions 8 (1969-85), 9 (1986-95) and 10 (1996-). The NCDR used the Norwegian versions of ICD-8 and ICD-9 and the English version of ICD-10.

\begin{tabular}{|c|c|c|c|c|}
\hline & Dementia diagnosis & Dementia type & $\mathrm{N}^{\mathrm{a}}$ & $\mathrm{N}^{\mathrm{b}}$ \\
\hline \multirow[t]{2}{*}{ ICD-8 } & 290.0 Senile dementia & & 24,381 & 2421 \\
\hline & 290.1 Presenile dementia & & 1027 & 340 \\
\hline \multirow[t]{6}{*}{ ICD-9 } & 290.0 Senile dementia, uncomplicated & & 21,490 & 4991 \\
\hline & 290.1 Presenile dementia & & 1113 & 482 \\
\hline & 290.2 Senile dementia with delusional or depressive features & & 29 & 5 \\
\hline & 290.3 Senile dementia with delirium & & 1 & 1 \\
\hline & 290.4 Arteriosclerotic dementia & Vascular & 996 & 318 \\
\hline & 331.0 Alzheimer's disease & $\mathrm{AD}$ & 1046 & 482 \\
\hline \multirow[t]{5}{*}{ ICD-10 } & F00 Dementia in Alzheimer's disease & $\mathrm{AD}$ & 1977 & 0 \\
\hline & F01 Vascular dementia & Vascular & 3581 & 1309 \\
\hline & F02 Dementia in other diseases classified elsewhere & & 243 & 0 \\
\hline & F03 Unspecified dementia (including presenile and senile dementia) & & 39,411 & 14,194 \\
\hline & G30 Alzheimer's disease & $\mathrm{AD}$ & 12,571 & 6547 \\
\hline
\end{tabular}

\footnotetext{
${ }^{a}$ Number of deaths with the actual diagnosis coded as underlying or contributory cause of death in the NCDR

${ }^{b}$ Number of deaths with the actual diagnosis coded as underlying cause of death in the NCDR

$\mathrm{AD}=$ Alzheimer's disease
}

\section{MATERIALS AND METHODS}

The present study is based on data from the NCDR. In Norway all death certificates are originally filled out by the local medical practitioners (see (13) for a death certificate template with guidelines), and then controlled and coded for the NCDR by Statistics Norway. In the coding process, the information on the death certificates is translated into ICD (International Classification of Diseases) codes. All deaths in the NCDR have an underlying cause (the illness or injury that started the sequence of conditions that led to death, or the outer circumstances of the accident or act of violence that caused the lethal injury). Most deaths also have one or more contributory causes coded. The maximum number of contributory causes coded in the NCDR was two in 1956-68 (ICD-7), three in 1969-95 (ICD 89), six in 1996-2004 (ICD-10), and from 2005 onwards there was no upper limit (the data program ACME Automated Classification of Medical Entities - has been used since 2005 to choose the underlying cause of death from all causes mentioned on the death certificate, based on logical rules developed by the WHO).

In 2003 there was a change in the national regulations for coding of causes of death, based on a list made by the WHO of diagnoses which may cause pneumonia, and therefore should be preferred to pneumonia as the underlying cause of death. Senile dementia was one of these diagnoses (14, p. 12).

ICD-7 had no specific coding for dementia, and deaths before 1969 have therefore not been included. The codes used for dementia in ICD 8-10 are given in Table 1. From 1996 (ICD-10), location of death was available, with nursing home as one alternative. More details on the history of the NCDR are given in e.g. (15).

We have calculated the age- and gender-specific proportion of deaths with any kind of dementia coded in the NCDR from 1969 through 2010, and with vascular dementia or AD coded from 1986. Separate analyses were done from 1996 for deaths occurring in nursing homes.

\section{ReSUlts}

In the study period 1,785,291 deaths were registered, of which 859,799 (48\%) were women (Table 2$)$. In women the proportion of deaths with dementia coded in the NCDR increased from $4 \%$ in 1969 to $15 \%$ in 2010 (Figure 1). The corresponding increase in men in the same time period was more modest, from $3 \%$ to $7 \%$. For the oldest age groups of the women the proportion was relatively constant in the 1970 s, followed by an increase in the $1980 \mathrm{~s}$, a more stable period in the 1990 s, and finally a marked increase in the 2000s. In the oldest male age groups there was only a modest increase from 1969 to about 2000, followed by a more marked increase after 2000.

In the period 1996-2010, 249,941 deaths took place in nursing homes $(39 \%$ of all deaths and $84 \%$ of all dementia deaths; Table 2), and of them 155,568 (62\%) were women. Also for these deaths the proportion with dementia coded in the NCDR increased, from $17 \%$ to $26 \%$ in women and from $13 \%$ to $18 \%$ in men (Figure 1). $77 \%$ of all nursing home deaths occurred at age 80 or older.

ICD-9 and ICD-10 (from 1986 onwards) had specific codes for subtypes of dementia (Table 1). In this period 1,093,665 deaths occurred. Of these, 79,633 (7.3\%) had dementia coded in the NCDR, and AD was reported in 13,633 cases $(1.2 \%)$ (cf. Table 2 ). The proportion of dementia deaths with $\mathrm{AD}$ coded increased from practically zero in 1986 to $28 \%$ in 2005 , and then declined slightly between 2005 and 2010 (Figure 2). The proportion with AD was much higher in the youngest age groups (Figure 2), but was relatively indepen- 
Table 2. From left to right for each time period: Number of deaths, percent women, percentage of all deaths that had dementia (general and specific types, cf. Table 1) coded in the NCDR, percentage of dementia deaths that had specific types of dementia coded in the NCDR. More than one sub-type may be coded for each death.

\begin{tabular}{|c|c|c|c|c|c|c|c|c|c|c|c|c|}
\hline & \multicolumn{4}{|c|}{ ICD-8, 1969-1985 } & \multicolumn{4}{|c|}{ ICD-9, 1986-1995 } & \multicolumn{4}{|c|}{ ICD-10, 1996-2010 } \\
\hline Diagnoses & Deaths (n) & $\begin{array}{c}\% \\
\text { ㅇ }\end{array}$ & $\begin{array}{l}\% \text { of } \\
\text { all } \dagger\end{array}$ & $\begin{array}{c}\% \text { of } \\
\text { dem. } \dagger\end{array}$ & Deaths (n) & $\begin{array}{c}\% \\
q\end{array}$ & $\begin{array}{l}\% \text { of } \\
\text { all } \dagger\end{array}$ & $\begin{array}{c}\% \text { of } \\
\text { dem. } \dagger\end{array}$ & Deaths (n) & $\begin{array}{l}\% \\
\text { + }\end{array}$ & $\begin{array}{l}\% \text { of } \\
\text { all } \dagger\end{array}$ & $\begin{array}{c}\% \text { of } \\
\text { dem. } \dagger\end{array}$ \\
\hline Any & 691,626 & 46 & & & 450,714 & 48 & & & 642,951 & 51 & & \\
\hline Dementia $^{a}$ & 25,408 & 61 & 3.7 & 100.0 & 24,629 & 68 & 5.5 & 100.0 & 55,004 & 67 & 8.6 & 100.0 \\
\hline $\mathrm{AD}^{\mathrm{b}}$ & & & & & 1,046 & 59 & 0.2 & 4.3 & 12,587 & 65 & 2.0 & 22.9 \\
\hline Vascular $^{\mathrm{b}}$ & & & & & 966 & 58 & 0.2 & 3.9 & 3581 & 57 & 0.6 & 6.5 \\
\hline
\end{tabular}

\begin{tabular}{|c|c|c|c|c|c|c|c|c|c|}
\hline & \multicolumn{4}{|c|}{ ICD-8,9,10, 1969-2010 } & \multicolumn{5}{|c|}{ Nursing homes, ICD-10, 1996-2010 } \\
\hline Diagnoses & Deaths (n) & $\begin{array}{l}\% \\
\% \\
\text { 우 }\end{array}$ & $\begin{array}{c}\% \text { of all } \\
\dagger\end{array}$ & $\begin{array}{c}\% \text { of } \\
\text { dem. } \dagger\end{array}$ & Deaths $(\mathrm{n})$ & $\begin{array}{l}\% \\
\text { \% }\end{array}$ & $\begin{array}{l}\% \text { of } \\
\text { all } \dagger\end{array}$ & $\begin{array}{c}\% \text { of } \\
\text { dem. } \uparrow\end{array}$ & $\begin{array}{c}\% \text { of } \\
\text { ICD } 10 \dagger^{\mathrm{c}}\end{array}$ \\
\hline Any & $1,785,291$ & 48 & & & 249,941 & 62 & & & 38.9 \\
\hline Dementia $^{a}$ & 105,041 & 66 & 5.9 & 100.0 & 46,431 & 69 & 18.6 & 100.0 & 84.4 \\
\hline $\mathrm{AD}^{\mathrm{b}}$ & 13,633 & 64 & 0.8 & 13.0 & 10,399 & 67 & 4.2 & 22.4 & 82.6 \\
\hline Vascular $^{\mathrm{b}}$ & 4547 & 57 & 0.3 & 4.3 & 3060 & 58 & 1.2 & 6.6 & 85.5 \\
\hline
\end{tabular}

${ }^{a}$ Deaths with dementia coded as underlying or contributory cause

${ }^{b}$ Deaths with diagnoses corresponding to this specific type of dementia coded as underlying or contributory cause (cf. Table 1)

${ }^{\mathrm{c}}$ The percentage of all deaths with the given diagnoses in 1996-2010 that took place in nursing homes.

$\mathrm{AD}=$ Alzheimer's disease

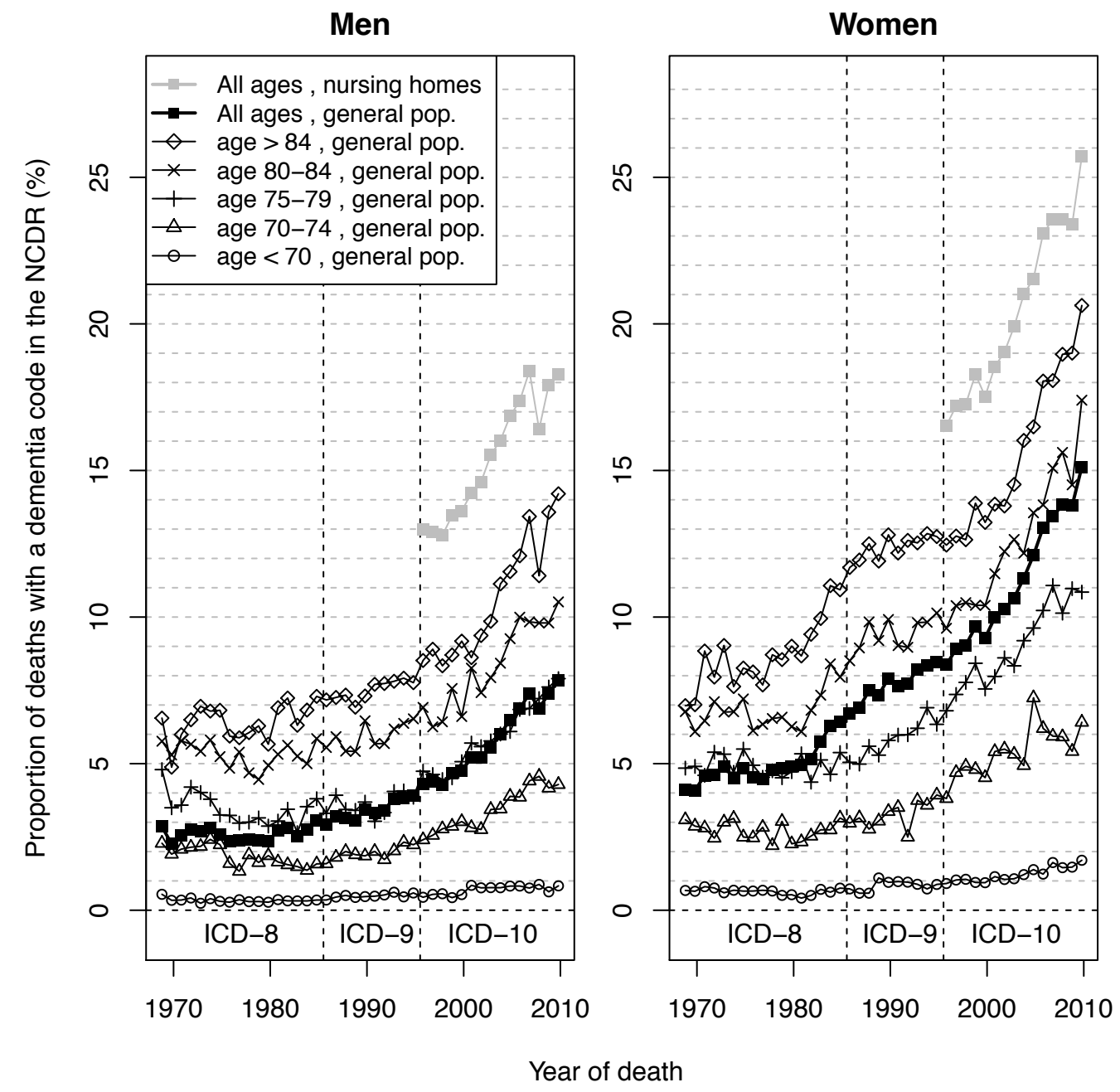

Figure 1. Proportion of all deaths in the general population from 1969 and in nursing homes from 1996 with dementia coded as underlying or contributory cause of death in the NCDR, stratified by gender and age at death. Dashed vertical lines indicate revisions of ICD. 

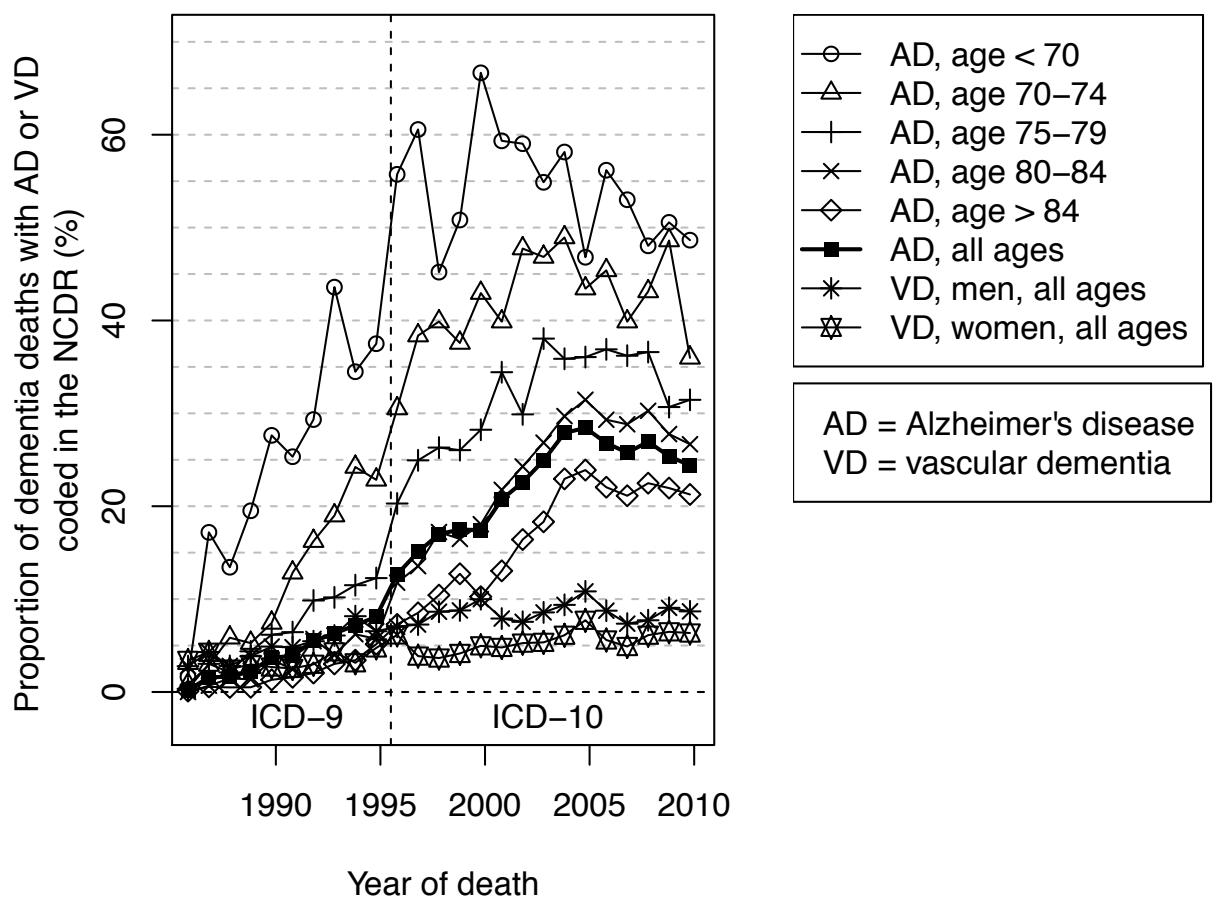

Figure 2. Proportion of dementia deaths from 1986 to 2010 with Alzheimer's disease and vascular dementia coded as underlying or contributory cause of death in the NCDR. For Alzheimer's disease both genders are joined together. The dashed vertical line indicates the introduction of ICD-10.

Table 3. Number (percentage) of deaths in 2005-2010 with dementia coded as underlying or contributory cause of death in the NCDR by dementia type, gender and age. Percentages are of all deaths in 2005-2010.

\begin{tabular}{|c|c|c|c|c|c|c|}
\hline \multirow[b]{2}{*}{ Type of dementia } & & \multicolumn{5}{|c|}{ Age at death (years) } \\
\hline & & $<70$ & $70-74$ & $75-79$ & $80-84$ & $>84$ \\
\hline \multirow{3}{*}{ All types } & Men & $273(0.8)$ & $474(4.2)$ & $1203(7.1)$ & $2231(9.9)$ & $4399(12.7)$ \\
\hline & Women & $312(1.5)$ & $479(6.2)$ & $1379(10.5)$ & $3402(14.9)$ & $11,893(18.6)$ \\
\hline & All & $585(1.1)$ & $953(5.0)$ & $2582(8.5)$ & $5633(12.4)$ & $16,292(16.5)$ \\
\hline \multirow{3}{*}{$\mathrm{AD}$} & Men & $128(0.4)$ & $177(1.6)$ & $393(2.3)$ & $582(2.6)$ & $1019(3.0)$ \\
\hline & Women & $167(0.8)$ & $229(3.0)$ & $502(3.8)$ & $1054(4.6)$ & $2574(4.0)$ \\
\hline & All & $295(0.5)$ & $406(2.1)$ & $895(3.0)$ & $1636(3.6)$ & $3593(3.6)$ \\
\hline \multirow{3}{*}{ Vascular } & Men & $26(0.1)$ & $56(0.5)$ & $135(0.8)$ & $230(1.0)$ & $299(0.9)$ \\
\hline & Women & $12(0.1)$ & $25(0.3)$ & $98(0.7)$ & $230(1.0)$ & $712(1.1)$ \\
\hline & All & $38(0.1)$ & $81(0.4)$ & $233(0.8)$ & $460(1.0)$ & $1011(1.0)$ \\
\hline \multirow{3}{*}{ Neither AD nor vascular } & Men & $121(0.4)$ & $242(2.1)$ & $682(4.0)$ & $1432(6.3)$ & $3102(9.0)$ \\
\hline & Women & $134(0.6)$ & $227(2.9)$ & $792(6.0)$ & $2136(9.4)$ & $8641(13.5)$ \\
\hline & All & $255(0.5)$ & $469(2.5)$ & $1474(4.9)$ & $3568(7.9)$ & $11,743(11.9)$ \\
\hline
\end{tabular}

$\mathrm{AD}=$ Alzheimer's disease

dent of gender (data not shown). For the youngest age groups most of the increase in frequency of the Alzheimer's diagnosis occurred in the ICD-9 period, i.e. 1986-1995, and for those who died 70 years or younger, a decreasing trend was observed in the ICD-10 period. For those aged 80 or older at death, most of the increase in the prevalence of AD occurred between 1995 and 2005.

The proportion of dementia deaths with vascular dementia coded in the NCDR increased only slightly in the period 1986-2010 (Figure 2). The proportion of all deaths with vascular dementia coded in the period
2005-2010 was similar for men and women in all age groups (Table 3), whereas the proportion of $\mathrm{AD}$ and other dementia types was higher in women in all age groups (Table 3).

The use of a dementia diagnosis as the underlying cause of death in deaths with dementia coded in the NCDR increased drastically from a minimum of $6.2 \%$ $(\mathrm{N}=88)$ in 1972 (both genders joined together) to a maximum of 50.6\% $(\mathrm{N}=2242)$ in 2009 (Figure 3). There are two major leaps in the dementia curves in Figure 3, one following the introduction of ICD-9 in 1986, the other following the national revision of the 

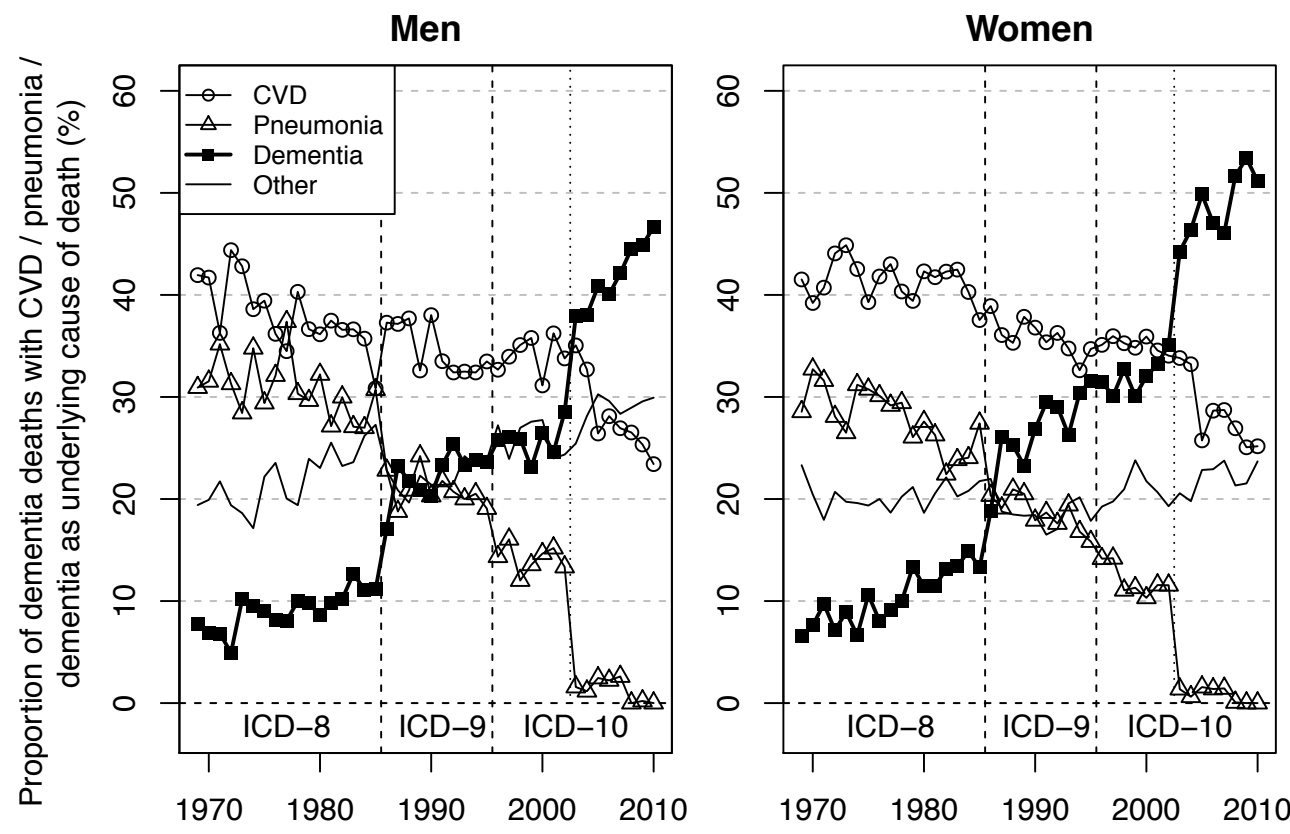

Year of death

Figure 3. Underlying cause of death in deaths where dementia was coded in the NCDR. Dashed vertical lines indicate revisions of ICD. The dotted vertical line indicates the change in national directions in 2003.

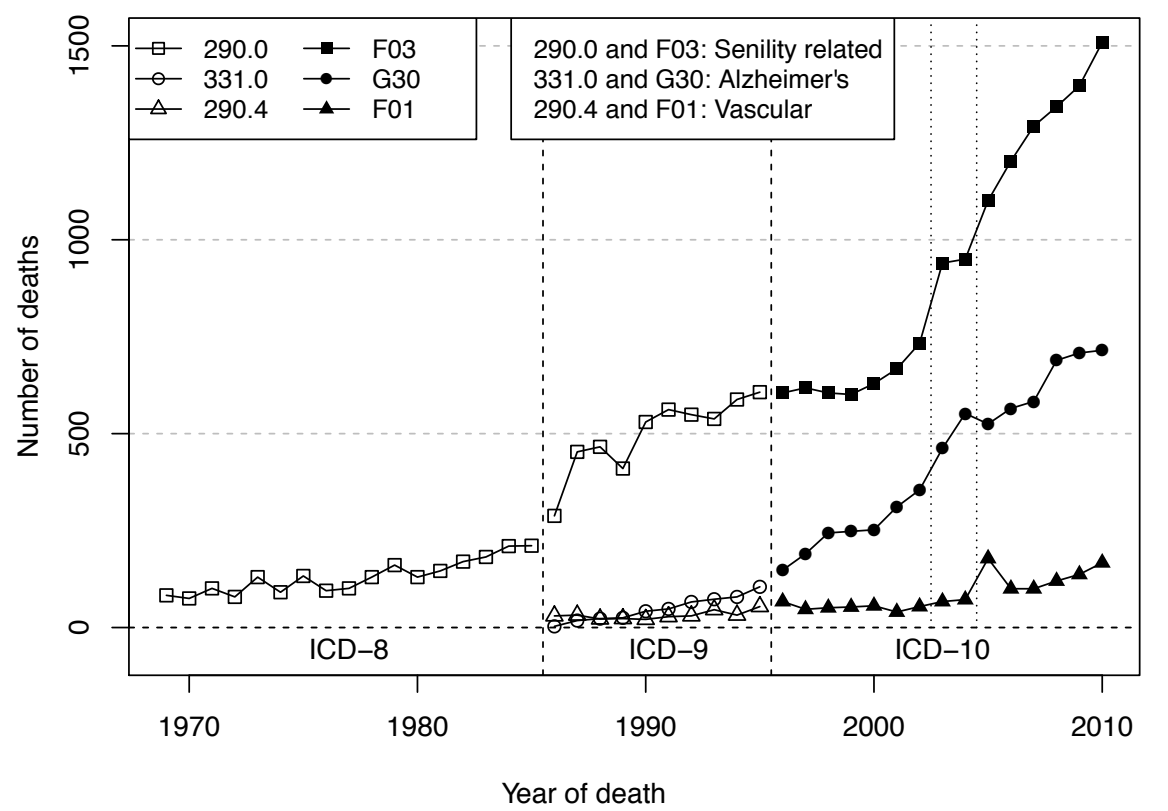

Figure 4. Number of deaths with the specific diagnoses coded as underlying cause of death in the NCDR. Only the most prevalent diagnoses within each category (senility related dementia, Alzheimer's and vascular dementia) are shown (cf. Table 1). Dashed vertical lines indicate revisions of ICD. Dotted vertical lines indicate the change in national directions in 2003 and the introduction of ACME in 2005.

directions for coding of causes of death in 2003 (14, p. 12). In both cases, there was a corresponding decrease in the use of pneumonia as the underlying cause of death, and in both cases it was senility-related dementia diagnoses that increased most (Figure 4). After the revision in 2003, pneumonia has seldom been used as underlying cause in dementia deaths (Figure 3).

\section{DISCUSSION}

Although the prevalence of dementia diagnoses in the NCDR roughly tripled from 1969 to 2010, there was still an apparent underreporting in 2010. It should be noted, though, that there is no one-to-one relationship between the following three factors: i) having demen- 
tia at the time of death, ii) having dementia reported on the death certificate, and iii) having dementia coded in the NCDR. Ideally, there should be a one-to-one relationship between ii) and iii), but not between i) and ii) since it is not required to register a disease on the death certificate unless it is relevant as a cause of death $(16, \S 4.1 .1)$. Dementia may for example be irrelevant in deaths from traffic accidents. As regards the relationship between death certificates and the NCDR, the number of contributory causes coded in the NCDR was limited in the early versions of ICD, and it might therefore in some cases have been impossible to include all information on the death certificates into the NCDR. The upper limit of contributory causes in the NCDR increased from three in ICD-8 (1969-85) to six in ICD-9 (1986-95). However, there was no discontinuity in the dementia prevalence in the NCDR between 1985 and 1986, indicating that this has not been a real problem in our data. We may thus assume that the prevalence of dementia on death certificates is well reflected by the prevalence of dementia in the NCDR during the period we have considered.

Also, when comparing dementia prevalence in the NCDR with prevalence estimates of dementia in the general population it should be kept in mind that the latter are uncertain. For example, the estimates in (2) of $31.7 \%$ and $40.7 \%$ in the age groups $85-89$ and $90+$, respectively, are much higher than the estimate in (4) for Western Europe of $24.8 \%$ in the age group $85+$.

The proportion with dementia coded in the NCDR roughly tripled from the 1970 s to 2010 . In the age groups 70-74 and 75-79 years the proportion in 20052010 was actually somewhat higher than the population estimates in both the Delphi consensus study for Western Europe (4) and in a report from the Norwegian Directorate of Health and Welfare (2). This does, however, not necessarily imply an over-reporting of dementia in the NCDR, as the prevalence of dementia among dead 70-79 year olds might be higher than among living 70-79 year olds. In the older age groups the prevalence of dementia coded in the NCDR was lower than earlier reported population estimates $(2,4)-$ in particular compared to the estimates of $18 \%$ and $\sim 35 \%$ in the age groups $80-84$ and $85+$, respectively (2). The fact that the proportion was still increasing in 2010 for the oldest age groups (Figure 1) also indicates an under-reporting of dementia in the NCDR for these age groups.

The discrepancy between the NCDR and prevalence estimates was even larger in the nursing home population $(23 \%$ had dementia coded in the NCDR in 2010 , compared to an estimated dementia prevalence in nursing homes in 2005 of about $80 \%$ (11)). This may be partly explained by the finding that many people with dementia in nursing homes do not have a dementia diagnosis (11), but probably many of those who actually have a diagnosis also fail to get dementia noted on the death certificate. A study comprising 92 deaths in 10 nursing homes in the Oslo area in 1990-91 reported a sensitivity of $38 \%$ for recording dementia on the death certificate compared with CDR (12).

An under-reporting of dementia on death certificates (low sensitivity) has also been reported in other countries (17-19). The specificity of dementia on death certificates, on the other hand, seems to be good. A Swedish study reported a specificity of $100 \%$ for the national cause of death registry, but a sensitivity of only $28 \%$ (20). The low sensitivity may be explained by doctors being reluctant to use the dementia diagnosis on the death certificate, for instance if the patient has not being assessed for a dementia diagnosis when alive.

The higher prevalence of dementia on death certificates in women than in men - in particular for AD and other non-vascular types - probably reflects a higher dementia prevalence in women in the general population $(5,6)$.

Although the reporting of $\mathrm{AD}$ on death certificates was dramatically higher in 2010 than in $1996,25 \%$ of all dementia deaths is still a low proportion compared to the population estimate of $50-70 \%$ (3), and it has actually been slightly decreasing since 2005 . There could be many reasons for this. First, we would argue that still many physicians do not recognize dementia in persons above the age of 75 years to be caused by AD. Since many of the oldest have several disorders that may lead to cognitive and functional impairments, many physicians would rather like to use the term unspecified dementia or simply omit to report dementia. Second, as many old patients in nursing homes with severe signs of dementia do not have a dementia diagnosis in their records, the physician that writes the death certificate will not report such a diagnosis (11).

According to changes in the national directions for coding of causes of death in 2003, senile dementia was from then on to be preferred before pneumonia as underlying cause $(14$, p. 12). The implementation of this change was evidently successful, as there were very few dementia deaths after 2002 with pneumonia as underlying cause, and the increase in dementia as underlying cause mainly came from an increase in senility-related dementia diagnoses.

There are specific diagnoses for senility in versions 8,9 , and 10 of ICD (Table 4). In an earlier study of dementia deaths in Norway in the period 1969-1983 (ICD-8), the diagnosis of senility was also considered

Table 4. Number of deaths in Norway 1969-2010 with senility diagnoses according to International Classification of Diseases (ICD), Revisions 8 (1969-85), 9 (1986-95) and 10 (1996-) coded in the NCDR.

\begin{tabular}{llrr}
\hline & Senility diagnosis & $\mathrm{N}^{\mathrm{a}}$ & $\mathrm{N}^{\mathrm{b}}$ \\
\hline ICD-8 & 794 Senility without mention of psychosis & 6328 & 6212 \\
ICD-9 & 797 Senility without mention of psychosis & 5083 & 5053 \\
ICD-10 & R54 Senility & 34,158 & 6980 \\
\hline
\end{tabular}

${ }^{a}$ Number of deaths with the actual diagnosis coded as underlying or contributory cause of death

${ }^{\mathrm{b}}$ Number of deaths with the actual diagnosis coded as underlying cause of death 
(21). Some dementia deaths in our study might have been coded as senility, but if we had included all senility diagnoses as dementia, the proportion of dementia deaths for all ages in Figure 1 would only have increased by $0.5-1$ percentage points in men and 1-2 percentage points in women in the ICD-8 and ICD-9 periods (data not shown). In the ICD-10 period, however, including senility diagnoses as dementia would have increased the dementia prevalence by 2-3 and 5-7 percentage points in men and women, respectively (data not shown). Due to this discontinuity in the use of senility as a contributory cause between ICD-9 and ICD-10 (see also Table 4) senility was not included in the present study.

The under-reporting of dementia on death certificates and in the NCDR have implications for epidemiological studies of risk factors for dementia where dementia death is used as a surrogate for dementia, depending on whether the under-reporting is random or not. For example, if it is more likely that a demented non-smoker than a demented smoker has dementia reported on the death certificate, the risk of dementia associated with smoking would be under-estimated. In case of random under-reporting, associations would be biased towards the null hypothesis due to loss of power. However, whether the under-reporting actually is random, we normally do not know ('under-reporting' in the context of risk factor analysis means that the number of deaths with dementia coded in the NCDR is smaller than the number of deaths where the dead had dementia. In this meaning of the word there would be some extent of under-reporting even though dementia was coded in all deaths where it was relevant).

\section{CONCLUSION}

There has been a marked increase in reporting of dementia on death certificates during the last four decades - in particular as underlying cause of death but in 2010, still many old persons with dementia died without having dementia reported on the death certificate. Even though estimates of dementia in the general population are uncertain, the large discrepancy between prevalence estimates and cases reported on death certificates in nursing homes clearly indicates an underreporting in the oldest age groups. The agreement between population prevalence estimates and death certificates was better for deaths occurring before the age of 80 . Reporting of $\mathrm{AD}$ on death certificates increased markedly from 1986 to 2005 , and has been relatively stable since then, but at a low rate compared to the estimated prevalence in the population.

\section{REFERENCES}

1. Launer LJ. Counting dementia: There is no one "best" way. Alzheimer's \& Dementia 2011; 7 (1): 10-14.

2. Sosial- og helsedirektoratet. Glemsk, men ikke glemt. Om dagens situasjon og framtidas utfordringer for å styrke tjenestetilbudet til personer med demens, 2007. http://www.helsedirektoratet.no/publikasjoner/glemskmen-ikke-glemt-rapport-om-demens/Publikasjoner/glemsk-men-ikke-glemt.pdf.

3. Qiu C, De Ronchi D, Fratiglioni L. The epidemiology of the dementias: an update. Curr Opin Psychiatry 2007; 20 (4): 380-385.

4. Ferri CP, Prince M, Brayne C, et al. Global prevalence of dementia: a Delphi consensus study. Lancet 2005; 366 (9503): 2112-2117.

5. Andersen K, Launer LJ, Dewey ME, et al. Gender differences in the incidence of AD and vascular dementia: The EURODEM Studies. EURODEM Incidence Research Group. Neurology 1999; 53 (9): 1992-1997.

6. Lobo A, Launer LJ, Fratiglioni L, et al. Prevalence of dementia and major subtypes in Europe: A collaborative study of population-based cohorts. Neurology 2000; 54 (11 Suppl 5): S4-S9.

7. Mathillas J, Lövheim H, Gustafson Y. Increasing prevalence of dementia among very old people. Age Ageing 2011; 40 (2): 243-249.

8. Schrijvers EMC, Verhaaren BFJ, Koudstaal PJ, Hofman A, Ikram MA, Breteler MMB. Is dementia incidence declining? Trends in dementia incidence since 1990 in the Rotterdam Study. Neurology 2012; 78 (19): 14561463.

9. Brunborg H, Texmon I. Befolkningsframskrivninger 2010-2060. Økonomiske Analyser 4/2010.

10. Norwegian Institute of Public Health. Cause of Death Registry, 2012. http://www.fhi.no/eway/default.aspx? pid=238\&trg=MainArea_5811\&MainArea_5811=5903:0:15,5160:1:0:0::0:0.

11. Selbæk G, Kirkevold Ø, Engedal K. The prevalence of psychiatric symptoms and behavioural disturbances and the use of psychotropic drugs in Norwegian nursing homes. Int J Geriatr Psychiatry 2007; 22 (9): 843-849.

12. Bjertness E, Torvik A, Ince PG, Edwardson JA. Validation of Norwegian death certificates on dementia in residents of nursing homes. Epidemiology 1998; 9 (5): 584-586.

13. Sosialdepartementet. Legeerklæring om dødsfall/melding om unaturlig dødsfall, 2012. http://www. helsedirektoratet.no/publikasjoner/legeerklering-om-dodsfall-melding-om-unaturlig-dodsfall/Publikasjoner/ legeerklering-om-dodsfall-melding-om-unaturlig-dodsfall.pdf.

14. Statistisk sentralbyrå. NOS D 411: Dødsårsaker 1995-2006, 2009. http://www.ssb.no/nos_dodsarsak/nos _ d411/nos_d411.pdf. 
15. Gjertsen F. Dødsårsaksregisteret - en viktig datakilde for medisinsk forskning. Tidsskr Nor Legeforen 2002; 122 (26): 2551-2554.

16. World Health Organization. International classification of diseases and related health problems, tenth revision, volume 2, 2004. http://www.who.int/classifications/icd/ICD-10_2nd_ed_volume2.pdf.

17. Macera CA, Sun RK, Yeager KK, Brandes DA. Sensitivity and specificity of death certificate diagnoses for dementing illnesses, 1988-1990. J Am Geriatr Soc 1992; 40 (5): 479-481.

18. Ganguli M, Rodriguez EG. Reporting of dementia on death certificates: a community study. J Am Geriatr Soc 1999; 47 (7): 842-849.

19. Zilkens RR, Spilsbury K, Bruce DG, Semmens JB. Linkage of hospital and death records increased identification of dementia cases and death rate estimates. Neuroepidemiology 2009; 32 (1): 61-69.

20. Jin YP, Gatz M, Johansson B, Pedersen NL. Sensitivity and specificity of dementia coding in two Swedish disease registries. Neurology 2004; 63 (4): 739-741.

21. Flaten TP. Mortality from dementia in Norway, 1969-83. J Epidemiol Community Health 1989; 43 (3): $285-$ 289. 